\title{
Peer Socialization into Gendered L2 Mandarin Practices in A Study Abroad Context: Talk in The Dorm
}

\author{
Wenhao Diao \\ Department of East Asian Studies \\ The University of Arizona \\ Email: wdiao@email.arizona.edu
}

Phone: (520) 621-0106

Address: 1512 E First St., 102 Learning Services Building, Tucson, Arizona, U.S.A. 85721

\section{Acknowledgements}

I am indebted to Drs. Mariana Achugar, G. Richard Tucker, Yueming Yu, and Patricia Duff. Their generous support made this project possible. I also thank the three anonymous reviewers and the journal editor for their insightful comments on earlier versions of the manuscript. All remaining errors are my own.

\section{Bio}

Wenhao Diao is an Assistant Professor in the Department of East Asian Studies at the University of Arizona. She is also an affiliated faculty member in the graduate program of Second Language Acquisition and Teaching (SLAT). She holds a Ph.D. in SLA from Carnegie Mellon University in Pittsburgh, Pennsylvania. 


\title{
Peer Socialization into Gendered L2 Mandarin Practices in A Study Abroad Context: Talk in The Dorm
}

\begin{abstract}
This article reports on the peer socialization of gendered Mandarin practices between three American students and their Chinese roommates in a college dorm in China. Gender is often perceived to be a salient identity category among adult L2 learners overseas. Drawing on the language socialization framework (Ochs and Scheiffelin 1984), this study focuses on how gender is constructed and indexed through language as the American students learn to use Mandarin sentence-final particles. Sentence-final particles constitute a unique repertoire to achieve affective work in Mandarin. They have further become a resource among China's urban youth to enact a cute female speech style. In this case study, I employ a qualitative approach with an embedded quantitative component to examine the participants' use of the particles over the course of one semester. The findings show how the American students become socialized into using these particles as gendered linguistic practices in the dorm conversations.

Keywords: language socialization, Mandarin, study abroad, gender, sentence-final particles, second language learning
\end{abstract}




\section{Introduction}

Study abroad in China is becoming increasingly popular among students in North America. Yet there is not much research that addresses how Mandarin language education socializes American sojourners in China (Duff 2008a: 117). The current study draws from the language socialization (LS) paradigm and explores the peer socialization processes between a cohort of American college students and their Chinese roommates as they lived together in a dorm in Shanghai. The focus is their engagement in gendered Mandarin practices.

Gender is a salient identity category among college-age L2 learners overseas (Kinginger 2008; Polanyi 1995; Talburt and Stewart 2010; Twombly 1995). Yet, with the exception of a few studies regarding Japanese (Iwaskaki 2011; Siegal 1995), research on study abroad has rarely examined learners' engagement in linguistic construction of gender. From sociolinguistic research, we know that gender is a crucial dimension of social differences that can be constructed and indexed through language (Eckert and McConnell-Ginet 2013). As American college students are shown to be linguistically performing gender and even policing sexuality amongst themselves when speaking English (Kiesling 2002; 2004), we are left to wonder in what ways gender can be experienced and enacted in other languages when these young adults go abroad.

Situated against this backdrop, this study explores how American college students are socialized into gendered linguistic practices when learning Mandarin in China. To do so, it draws on the LS paradigm as its theoretical framework. LS refers to the dual processes by which children and other novices socialize with experienced speakers through language and are socialized by the latter into local cultural discourses (Ochs and Schieffelin 1984). This study focuses on peer LS into gendered Mandarin practices. In particular, it examines Mandarin L2 learners' engagement in using affective sentence-final particles (ASPs) as gendered linguistic 
practices. These ASPs include $a / y a$ (written as 啊/呀), la (啦), $m e$ (嘛) ${ }^{1}, o$ (哦), eh/ye (呃/耶)

(Starr 2011). The rationale for studying them is multifold. First of all, expressions of emotions are often ideologically linked with women (Eckert and McConnell-Ginet 2013: 158), and Mandarin ASPs constitute a unique repertoire for its speakers to achieve various kinds of affective work (Wu 2004). Such uniqueness makes them ideal for LS research. Secondly, social meanings of linguistic features are historically situated and culturally shaped. Similar to the Japanese sentence-final particles that became semiotically linked to women when Japan transformed into a capitalist state (Inoue 2002), the Mandarin ASPs are also becoming indexical of gender in an increasingly capitalist China, where construction of social differences such as gender is now central (W. Zhang and Kramarae 2012: 767). The association between ASPs and a female speech style has its origin in Taiwan (Farris 1994). As women in China today appropriate linguistic practices from Taiwan to perform gender (Q. Zhang 2007), these ASPs are also becoming resources for them to enact an infantilized persona and to evoke traditional expectations for women to be 'powerless' (Chuang 2005). When sojourners in China learn to use them in context, they also engage in culturally embedded ways of speaking. Lastly, linguistic features indexical of gender often contain multiple meanings and can be highly productive if acquired by novice language users (Ochs 1992). The ASPs are no exception. They are used very frequently in everyday life, carrying meanings such as region (Callier 2007; Starr 2011) and politeness (Lee-Wong 1998) in addition to gender. Yet formal Mandarin instruction often does not adequately address the use of the ASPs (Bourgerie 1996); even less so regarding their emerging meaning associated with gender. The discrepancy between language teaching and everyday linguistic practice further motivates this study's desire to address the learning of these ASPs among students who study abroad. 
In what follows, I first review the research on gender and linguistic construction of gender in the study abroad context. I then focus on three American students (one female, two male) living with their Chinese roommates in a Chinese college dorm. My analysis examines their engagement in gendered Mandarin practices and illustrates how they use the ASPs to index gender. As I show instances of policing sexuality in their interactions, the findings further demonstrate how gender can intersect with sexuality in peer L2 socialization processes. By highlighting their socialization into emerging gendered linguistic practices, the study can improve our understanding of L2 learning during a sojourn overseas.

\section{Background}

Gender in study abroad research

Research on study abroad and L2 learning has witnessed a 'social turn' in recent years (Kinginger 2010a), shifting from measuring students' linguistic gains to qualitatively analyzing their experiences. Identity categories - particularly gender - are becoming a central theme in the literature (Kinginger 2009). Polanyi's (1995) study of female students' narratives of their experience in Russia showed instances of harassment, which likely contributed to their lack of L2 gains that was documented by Brecht, Davidson and Ginsberg (1995) for the same population. ${ }^{2}$ Following Polanyi's (1995) article, a number of studies have observed similar unpleasant encounters experienced by American women in various study abroad destinations, including Argentina (Isabelli-Garcia 2006), Costa Rica (Twombly 1995), France (Kinginger 2008), Mexico (Bacon 2002), Russia (Pellegrino Aveni 2005), and Spain (Talburt and Stewart 2010). At the same time, American men seem able to celebrate their gender when overseas, 
being free from anxiety (Pellegrino Aveni, 2005: 80-81) and even seen as men of 'heroism' and 'valor' (Kinginger 2008: 91).

The stories in these studies are compelling and the contrast between the men and women is intriguing. Yet because the scope of these inquires is often limited to the perspectives of the American students, who probably neither fully understand 'the local meanings of actions and utterances' nor 'stay long enough to develop such an awareness' (Kinginger 2010b: 221), it remains unclear how the students actually interact with the local people and to what extent they appropriate local ways of performing identities such as gender (Kinginger 2009: 204; Wang 2010). Up until this point, research on overseas sojourners' socialization into gendered L2 practices remains relatively scarce. I now turn to discussion of the research on LS in the study abroad context with a focus on gendered linguistic practices.

\section{Socialization into gendered linguistic practices during study abroad}

Many of the existing studies on study abroad students' socialization into gendered L2 practices have focused on learners of Japanese. Siegal (1995), for example, shows how four Western women became aware of the submissive gender roles the Japanese honorific forms index and resisted using them in their own language. Iwasaki (2011), on the other hand, interviews four American men about their use of gendered forms after they studied in Japan. She reports that the formal form (desu/masu) was favored as a polite choice, even though the plain form has the potential to index masculinity in Japanese. Yet due to her reliance solely on students' recall of their experience, it is impossible for us to see how gender and politeness were negotiated in authentic discourse. More importantly, while these findings are doubtlessly related to the cultural traditions of gender in the Japanese society (Inoue 2002), the relationship between 
language and gender is certainly not unique to Japan.

If we examine the L1 socialization literature, learning ways to perform gender tends to be a central aspect of the process in various language contexts - and often in interactions between peers (Goodwin and Kyratzis 2012). This observation seems intuitive because LS research addresses how novices learn to communicate 'meaningfully, appropriately, and effectively' in and through social interaction (Ochs 1996: 408), and gender constitutes a crucial dimension of differences between peers (Eckert and McConnell-Ginet 2013). On the other hand, study abroad research also concerns how L2 learners become able to use pragmatic and interactive features appropriately. Issues that have been investigated include politeness with host parents and siblings in homestays (Cook 2006; 2008; Iino 2006), making requests in service encounters (Shively 2011), as well as alignment seeking (Ishita 2009) and turn construction (Author 2011; Dings 2007) in conversations. But, appropriateness can manifest itself in different ways in varying contexts. Talking to peers in a college dorm, for instance, can entail norms that are very different from speaking with senior members in the host family. Yet, with the exception of Shively's (2013) study that investigates the development of humor in Spanish, research in this line has typically not focused on interactions between peers and even more rarely on the peer socialization of gendered L2 practices. The oversight becomes particularly serious when we investigate the experience of American students in China, because they are in fact more likely to live in a dorm (Du 2013: 133). Programs in China tend to assign American students conversational partners or roommates who are usually local college students ${ }^{3}$, which further highlights the need to explore the peer L2 socialization processes in the Chinese context. Therefore, in this study about American students in China, the focus is interactions between peers and their engagement in gendered Mandarin practices. 
Emerging gendered linguistic practices among China's urban youth

Although China has experienced tremendous changes since the late 1970s, economic growth has not led to greater gender equality. As the country transitions from the genderdeemphasizing Maoist era to a time of state capitalism, the 'subservience' and 'compromise' of the underprivileged is highly valued and therefore improving women's status is no longer deemed a priority (Guo 2010: 64). Traditional ideologies are re-emerging and operating simultaneously with new gender discourses, creating different gendered linguistic practices among China's urban youth (W. Zhang and Kramarae 2012). While sometimes women can sound 'sharp,' more often their talk is expected to conform to conventional ideas such as 'gentle' and 'soft-voiced' (ibid: 766). The latter is evidenced in the spread of a speech style that is known in Mandarin as diă ('babyish') (Chan 1996; 1998) or sājiāo ('coquettish') (Farris 1988). It is linked to the historical gender discourse that imagines women to be powerless and expects them to gain sympathy from men (Chuang 2005). It can be construed through not only a higher pitch that indexes femininity almost universally (Eckert \& McConnell-Ginet 2013), but also frequent use of several sentence-final particles that are associated with little girls' talk (Chan 1998; Farris 1994). Collectively referred to as ASPs, these particles of interest here include a/ya, la, me, o, eh/ye (Starr 2011).

These ASPs are selected as the focus of the current study because the link between them and gender is culturally embedded and discursively constructed, which makes them a natural focus for L2 socialization research. Syntactically attached to the final position of an utterance, ASPs are thought to be void of referential meaning but can express attitudes, emotions, or (un)certainty in interactions (Luke 1990; Wu 2004). Gender ideologies commonly link emotional 
engagement with women's speech (Eckert and McConnel-Ginet 2013:158). As expressions of affect, these ASPs are also believed to index gender, particularly in Taiwan (e.g., Erbaugh 1985; Farris 1994). Shih (1984: 219) even goes so far as to explicitly state that they are features of women's language because women are 'more emotional.' Moreover, because frequent and exaggerated use of ASPs is associated with whining children who attempt to 'get their way from an unwilling parent' (Farris 1994: 302), women in Taiwan also use this style to manipulate their listeners by infantilizing themselves (Chuang 2005). Today the style has spread to college women in China (W. Zhang and Kramarae 2012). In a survey of 1,190 Chinese college students' language use on the Internet, $53.4 \%$ of the women reported 'very frequent' use of affective particles, as opposed to only $13.5 \%$ of the men (Z. Zhang 2008).

Yet, research to date has not found any simple gender effect on the actual use of ASPs in Mandarin communication (Callier 2007; Starr 2011). Z. Zhang (2008: 17) too suspects a discrepancy between women's self-reports in his survey and their actual ASP use, stating that they usually avoid sounding too emotional in real life because social norms expect them to be gentle and reserved, or in other words, 'lady-like' (shünü). His claim may seem to directly contradict Shih's (1984) belief that women sound more emotional, but taken together, they reveal a key aspect of linguistic features that can index gender: they are not used exclusively 'by, for or with people of a certain gender' (Ochs 1992: 340). As Starr (2011) shows, frequent use of ASPs is linked with traits such as being childish as well as emotional. These traits may apply to both genders, but more often they are ideologically associated with young women. Given the gender discourses in today's China that sometimes imagine modern women to be sharp-tongued but other times regard babyish talk to be attractive (W. Zhang and Kramarae 2012), ASPs can also be employed or avoided in different contexts to index a range of gendered personae. 
Another reason to focus on the learning and use of ASPs is their high frequency (Callier 2007) and productivity in everyday Mandarin communication. They encode multiple layers of social information such as politeness (Lee-Wong, 1998), region (southern Mandarin) (Callier 2007), and stance (Wu 2004). L2 learners will almost certainly encounter them when they interact with Mandarin speakers in natural settings. Nevertheless, ASPs are often overlooked in Mandarin instructional materials (Bourgerie 1996) and in research on the acquisition of Mandarin (Ke 2012). Even when they are addressed, the emerging meaning associated with gender is almost never taken into consideration.

The present study takes this gap as a point of departure by addressing the following research questions:

1. What opportunities became available for American students to socialize gendered linguistic practices with their peers in the dorm?

2. Do they engage in using the ASPs to construct and index gender? If so, how are meanings related to gender assigned and enacted among the students and their Chinese roommates?

\section{Methods}

Site

The data presented here came from a project conducted at a study abroad center in Shanghai during the spring of 2012. All students enrolled at the time had to select one of the two tracks the center provided - a language-intensive track or a language and culture track. The students on the former track took four hours of Mandarin classes (two more hours than those on the other track) everyday Monday through Friday. They were also required to live either with a 
Chinese roommate in a dorm or with a local family. The dorm building was designed specially for international students and not accessible to the local students (except for the registered Chinese roommates). Possibly due to the concentration of English-speaking international students in the building and their intensive curriculum, for the American students in the dorm, Chinese roommates were typically the people with whom they used Mandarin most often.

\section{Participants}

Twenty students volunteered to participate and completed the background survey and the pre-version of the Awareness of Mandarin Stance Markers questionnaire (AMSM), a questionnaire designed for the project that included a section on sentence-final particles (see the data section for more details about the survey and the questionnaire). The majority of these students were living in the dorm and half of them had a Chinese roommate (Table 1). ${ }^{4}$

Following the convention in case study research (Duff 2008b), four students were selected based on their gender, living arrangement, and scores in AMSM (both total and for the particle section). ${ }^{5}$ Of the four, three students who were living with Chinese roommates were selected as the focal students in this study (highlighted in bold in Table 1). Their Chinese roommates also became participants.

\section{[TABLE 1 NEAR HERE]}

The three students, Ellen, Tuzi, and Mac, all came from white U.S. families (Appendix 3). Ellen is female and the other two male. They had all taken formal Mandarin classes, but their histories of learning varied.

Ellen was placed into the most advanced language class at the program. Before her arrival in Shanghai, she had taken four semesters of Mandarin at her home institution in the U.S. 
and one semester at a language program in Harbin, China, where northern Mandarin (the base of standard Mandarin) was spoken. Born and raised in a conservative suburban part of Ohio, she was mistaken as a lesbian in high school and underwent great pressure from her religious family. She then developed an interest in studying gender and sexuality as well as alternative cultures. Her decision to come to Shanghai and live in the dorm was due to the city's reputation for being one of the most liberal in China and her hope to discuss issues related to sexuality with the local 'young people' (Ellen, pre-interview).

Tuzi's history of learning followed a different path. His Mandarin learning experience was primarily naturalistic immersion with some formal instruction. He had taught English for six months in Guangdong in southern China, where he picked up some Mandarin and Cantonese. However, he did not take any formal classes until his return to the U.S. He arrived in Shanghai after taking one semester of Mandarin at his home institution in Massachusetts. Having some knowledge of sociolinguistics, Tuzi was critical of the idea that there is one single standard language and expressed his disinterest in learning Beijing Mandarin. He viewed Shanghai as an alternative to Beijing and also a way to celebrate his identity as being from a large metropolis (New York) (Tuzi, post-interview).

Mac's experience with Mandarin is quite different from that of Ellen and Tuzi. Before coming to Shanghai, he had taken thirteen semesters of Chinese, including three years in high school and five semesters in college. However, of all the focal students, he was also the only one who had never been to China before. The primary reason he selected the program in Shanghai was that his home institution advised him that the city is more 'Western' and likely easier for him to adapt to. He chose to live in the dorm also because of his own desire for a relatively easier transition to Chinese culture (Mac, background survey). 
Their Chinese roommates were all college students enrolled in the hosting institution (see Appendix 3). They all had previously lived with American students. Although Shanghai has a local linguistic variety (Shanghainese), all of them came from Mandarin-speaking regions in China and did not speak Shanghainese. ${ }^{6}$

Helen was Ellen's roommate. She was a college senior studying applied Chinese linguistics. Growing up in Jiangsu, she spoke eastern Mandarin ${ }^{7}$ as her native tongue. She had lived in the U.S. for one semester, interning in Florida. At the time she was applying for graduate programs outside of Mainland China and was admitted by a university in Hong Kong. Tuzi’s roommate, Li, was also a college senior, majoring in computer science. He came from Henan where northern Mandarin was spoken. He was also applying for graduate programs overseas and was accepted by a university in New York. Fang was Mac's roommate. Like Helen, he too came from the eastern Mandarin-speaking region of Jiangsu. He was a junior and also majored in applied Chinese linguistics. While the spring semester normally ends in late June at the university, Fang's classwork was completed in early April so that he and his classmates could participate in internships. He was rarely seen in the dorm since the internship started.

\section{Data}

Data were collected from a multitude of sources: 1) Background surveys (Appendix 4). The surveys were adopted from the Language Contact Profiles (Freed, Dewey, Segalowitz, and Halter 2004) and fine-tuned for this study. 2) AMSM questionnaires (Appendix 5). Informed by Kinginger's (2008) Language Awareness Interviews, these questionnaires were designed to document the American students' awareness of pragmatic variations in Mandarin, including the use of sentence-final particles. They were distributed to all participants in the first week of the 
program, and to the focal students again in the final (fifteenth) week. 3) Audio-recorded interactions. Inspired by previous research on LS among students overseas (Shively 2011;2013) and interaction between peers in a comparable youth residential space (Kiesling, 2004), each focal student was given a recorder and instructed to record routine interactions with their Chinese roommates every week. The three students submitted a total of 1114 minutes of recorded interactions between themselves and their roommates (Table 2).

\section{[TABLE 2 NEAR HERE]}

4) Field observations. I conducted 48 hours of field observations and took notes. 5) Interviews. Semi-structured interviews were conducted with the focal students individually during the second and fifteenth weeks of the program. I also chatted with them and their roommates during my site visits.

\section{Analysis}

Both thematic and discourse analyses were conducted. For the thematic analysis, all qualitative data (interview transcripts, field notes, survey responses, recordings, and artifacts) were imported into NVivo 9. I then used NVivo to identify frequently recurring themes for each participant and analyzed them in a triangulated manner (Maxwell, 2005).

The discourse analysis followed research on Mandarin ASPs in conversations (Luke 1990; $\mathrm{Wu}$ 2004). The 1114-minute recordings were used as the corpus and transcribed. They were first transcribed in a basic manner (with topics, basic content, and the use of ASPs noted), because an initial transcript with too much information would be 'difficult to follow and assess' and therefore researchers must be 'selective' (Ochs 1979: 44). Then, after reviewing the initial 
transcript, I identified episodes in which the participants used the ASPs to organize their social (and particularly gender) relations and transcribed them in greater detail using Transcriber.

For further triangulation, each of the focal students' first and last recordings (submitted in early March and late May respectively) were included in a quantitative analysis (Table 3).

\section{[TABLE 3 NEAR HERE]}

The token numbers and frequencies of the ASPs were calculated (Starr 2011). In Sinitic languages the definition of a sentence can be controversial (Cumming 1984), and thus calculating the ASP frequency may be tricky. In my analysis, I used Tao's (1996: 11) notion of 'intonation units' (IU) ('prosodically segmented' units in naturally occurring utterances) to segment the units in the corpus (such as phrases and clauses). The ASP frequency was calculated as the percentage of IUs ending with an ASP in all Mandarin IUs. The Chinese roommates' use of ASPs was also analyzed. Certainly, it is possible for one's ASP frequency to fluctuate from time to time; however, as I examined the same interlocutors in identical situations at a stable site (the students and their Chinese roommates in dorm room conversations that lasted for at least 20 minutes), the results were still comparable.

\section{Findings}

The findings are presented below, organized by individual cases and concluded with a comparison across the cases and a summary. To answer the research questions, in each case I describe the features of their interactions and present episodes to show how gendered linguistic practices became relevant. As my research goal is most concerned with their use of ASPs, I also highlight how they engaged in using them to index gender, if this occurred. 
Ellen and Helen: 'Too cute a!'

The theme of gender recurred very frequently in Ellen and Helen's interactions, as the two women routinely discussed topics such as heterosexual relationships, marriage, and the female body. When asked what they typically talked about in conversations that were not recorded, they also named 'guys' and 'finding a boyfriend,' because according to Ellen, 'we are girls.' In their interactions, gender was also a dimension along which they arranged their linguistic and discursive practices. For instance, when Helen asked Ellen about courtship situations in the U.S. college culture ('what is a date?'), Ellen not only described what she considered to be a 'date,' but also said that, as women, they should not be the first to confess their affection (Field notes, 05/10/2012). These instances show that, as two college-age heterosexual women with the ability and the experience to travel overseas - and to each other's country, they became peers in many ways beyond being of similar age.

Their peer LS processes also evolved around gender and gendered practices. In Excerpt 1 below, Ellen is recalling how as a child she violated conventional norms for girls:

Excerpt 1: 'Becoming a man' or 'being like a boy' (04/19/2012. EL=Ellen; HL=Helen.)

1 EL danshi wo chuan de hen nanxinghua. wo shi zheyang de. but I wear PRT very masculine I COP such PRT

But I dressed in a masculine way. I was like that. suoyi wo changchang gen nansheng chaojia. so I often with boy quarrel So I often fought with boys.

3 changchang hui da tamen. often will hit they [I] often would hit them.

$4 \quad$ zai zhe ge- zhong (.) zhongxue de shihou. LOC this MSR middle middle-school PRT time When [I] was in the- middle, middle school

$5 \quad$ changchang shi wo de laoshi shuo. ((smacking lips)) often COP I PRT teacher say [it] often was my teacher saying

6 ((changing to a low voice)) aiyi. qing bie da na ge nansheng. please NEG hit that MSR boy Aiyi, please do not hit that boy.

7 HL: hhh. [heh heh heh heh.] 
EL: jiushi (.) changchang hui zheyang zuo. hhh.

just often will such do

[I] just would often do such things.

9 HL: shuoming ni xiao shihou hen- nanhaizi qi.

show you little time very boy feeling

[It] shows you were very much like a boy when you were little

Here, Ellen starts by labeling her childhood behaviors nánxinghuà ('masculine,' but literally 'becoming a man') (line 1). After hearing the story, Helen corrects her and teaches her the phrase nánháizi qì ('like a boy') (line 9). The two terms can both be found in China's youth culture, but when applied to women, they imply almost the opposite gender orientations. Nánxinghuà suggests women's transgender mentality/performances and hence the lack of attraction to men (Baike n.d.). On the contrary, the term nánháizi qì, according to a Chinese fashion magazine Chic! Exchange (2011), is considered to have origins in Taiwanese pop culture and indicates that certain unfeminine performances by women can still be considered 'cute.' This is because unlike nánxìnghuà ('becoming a man'), nánháizi qì ('like a boy') links women with young boys and thus infantilizes the former, a central process for women to be cute in Chinese gender discourses (Chuang 2005). Although from this excerpt alone we cannot assume that Ellen can fully recognize the differences between the terms, what is evident here is their engagement in discursive construction of gender as Helen helps her American peer to enact a gendered but not transgendered identity.

This way of organizing social practices in relation to gender is even more evident when they were using ASPs. Excerpt 2 is from a conversation in which Ellen used $a$ and $l a$ to enact a cute girl persona after she overheard a group of girls talking in the hallway:

Excerpt 2: 'Girls pretend to be cute.' (05/17/2012. EL=Ellen; HL=Helen.)

1 EL: nüren.

woman

Women. 
3 HL: nü-ren-

woman

Women.

wa ni shuo zhe ju hua de shihou jiu xiang ge nanren. hhh. you say this MSR speech PRT time just like MSR man Wow, when you said this sentence, [you were] just like a man. ((both laugh))

6 EL: tamen jiu shi fengzi athey just COP crazy ASP

They are just crazy ' $a$ '!

9 HL: dui nüsheng youshihou jiu hui zhuang ke'ai right girl sometimes just will pretend cute Right. Girls sometimes just pretend to be cute.

10 EL: dui. danshi danshi wo de yisi jiu shi
right but but I POS meaning just COP

Right. But but what I mean is just No-, actually regardless of how you look

ni de pengyou hui shuo ah! tai ke'ai a. you POS friend will say too cute ASP Your friends will say, "Ah! Too cute ' $a$ '." [tai \%sexy\% la] too ASP

"Too sexy 'la',"

14 HL: [dui dui dui]

right right right Right.

At the beginning of this interaction, Ellen was evaluated as sounding 'like a man' (line 4). She immediately gauged her speech style in the next turn by utilizing the ASP $a$ in Mandarin (line 6) and an elevated pitch in English (line 7). This juxtaposition, along with her remark that 'they are so cute,' demonstrates her meta-pragmatic awareness of the link between the ASPs and cuteness. Moreover, the ASPs in Ellen's lines co-occurred with lexical items such as 'cute' (line 11) and 
'sexy' (line 12). Throughout the episode of interaction, Helen also consistently confirmed the use of ASPs as a way to evoke the cute girl persona (lines 9 and 14).

To gain further insights into Ellen's learning of the ASPs, we can look at her ASP usage in the recordings. She did not use a single ASP in March's recording. In May, her ASP frequency increased to $8.08 \%$. Helen's ASP frequency also changed, dropping from $11.59 \%$ to $6.91 \%$. Her fluctuation may indicate that young female speakers of Mandarin do not have to use ASPs at a consistently high rate. Yet it is worth noting that she was the only female Chinese roommate among the focal participants, and both of these numbers were rather large compared to the rest of the group (all American students and the other two Chinese roommates).

\section{Tuzi and Li: 'That sounds gay.'}

Gender was also the most frequent theme in interactions between Tuzi and Li, but it was manifested through the enactment of 'heterosexual masculinity' (Kiesling 2002). Despite their different cultural backgrounds, the two men constructed a sense of solidarity by routinely talking about women and rating their attractiveness, which even took place when I, a female researcher, was present. Tuzi deemed such events to be normal, commenting to me, 'You are talking to two guys.'

Along with these frequent conversations about women, heterosexual masculinity also involved policing sexuality (Kiesling 2002) between the two men. Routine events such as their language tutorials became a place where sexuality was being examined and linguistic practices sanctioned accordingly. For example:

During the tutorial they encountered a word tèbié ('special') in the text. Tuzi tried the word in a sentence, 'nǔ hěn tèbié' ('You are special.'). Li replied immediately in 
Mandarin, 'Yes. But don't tell me this.' Tuzi laughed and said, 'So I should tell women that.' Li agreed. (Field notes. 03/07/2012.)

Here, as Li rejects the word tèbié, what we can see is not only an example of policing sexuality, but also Tuzi's immediate reaction that demonstrates his familiarity with the situation ('So I should tell women that.'). Similar events took place regularly in the data.

Policing of heterosexual masculinity can also be found in their use of ASPs. Tuzi had stayed in southern China for six months, where ASPs are used significantly more frequently (Callier 2007). After noticing it on TV, he imitated this linguistic practice and 'accidentally made a habit' (Tuzi, post interview), an instance of his 'implicit socialization' (Cook 2008) into local linguistic practices. After arriving in Shanghai, he was living with a male college student from a northern Mandarin-speaking region and their interactions often involved policing sexuality. His frequent use of ASPs was no longer seen as appropriate. Excerpt 3 is from a long discussion of ASPs after Li noticed Tuzi's frequent use of them and disapproved (see Appendix 6 for the complete episode of interaction):

Excerpt 3: 'That sounds gay.' (03/14/2012. TZ=Tuzi, LI=Li, WD=Researcher.)

1 LI: buyao buyao buyao.

NEG-want NEG-want NEG-want

Don't. Don't. Don't.

2 TZ bu [chengshi.]

NEG honest

Dishonest?

3 LI: [nande-]

$$
\text { male }
$$

Guys-

4 TZ: fan- fancheng? zhencheng. bu zhencheng. sincere NEG sincere ((Incomprehensible)). Sincere. Not sincere?

5 LI: nande- ting qilai xiang- xiang yi ge hhh gay hhh. male sound COMP like like one MSR gay GUYS sound like a- like a- gay. 
7 LI: ye bushi xiang gay la.

CONJ NEG like gay ASP

Not really like a gay.

8

$>$ jiushi $<$ jiushi xiang yi ge nüde.

just just like one MSR female

Just, just like a female.

9 TZ: xiang yi ge nüren.

like one MSR woman

Like a woman.

10

hao de.

okay PAR

Okay.

In the excerpt, though being told not to use the ASP $a$ (line 1), Tuzi's prior experience led him to argue that frequent use of ASPs was simply a regional feature associated with speakers in southern China (line 3). This observation was in fact consistent with empirical research (Callier 2007) and was acknowledged by his roommate Li (line 8). However, Li continued assigning meanings related to gender/sexuality to the ASPs ('gay' in line 19, 'female' in line 22), introducing Tuzi to the additional layer of social meanings. Tuzi eventually recognized them as indexical of gender and sexuality (lines 6, 9, 10).

The excerpt above is an instance of a complex LS process in which previous exposure to regional varieties intersected with discourses about gender/sexuality because of the multiple social meanings ASPs encompass. At the end of this conversation, Tuzi thanked Li, saying in Mandarin, 'Thank you for teaching me to be a man.' (Field notes, 03/14/2012.) Being 'a man' here was interpreted as heterosexual masculinity, and it could be constructed through language in the process of L2 learning. His 'habit' of frequent ASP use also changed over his semester in Shanghai. In his recording from March, $14.69 \%$ of all the Mandarin IUs ended with an ASP. The number dropped to only $5.64 \%$ in May. His roommate Li produced a consistently low frequency of ASPs, with $4.23 \%$ in March and $4.61 \%$ in May. 
Mac and Fang: 'Them foreign students.'

Mac's experience was qualitatively different from Ellen or Tuzi. His had rather limited interactions in Mandarin with the roommate Fang. Over the course of the 15-week semester, Mac was unable to submit any recordings for over three weeks. During those weeks, Fang was interning at an organization off campus and was rarely in the dorm. Mac's family also came to visit, which kept him away from the dorm for a week. Within the recordings that Mac submitted, English was almost always used. The total Mandarin IUs they produced in the recordings were far fewer than other participants. Their recording from March lasted 21-minutes, during which Fang produced only 103 Mandarin IUs and Mac only 69. In May’s 28-minute recording, Fang had 146 Mandarin IUs and Mac just 34, even fewer than in March.

Within their limited conversations in Mandarin, the theme of gender did not occur. ASPs were also completely absent in Mac's utterances. His roommate Fang used ASPs but there was a sharp decrease, dropping from $13.59 \%$ in March to only $2.05 \%$ in May. A close examination of the recordings shows that Fang used more ASPs in March because his girlfriend was present during the recording (see Appendix 7 for an excerpt). In the IUs he uttered to her, $16.23 \%$ ended with an ASP. When eliminating them from the analysis, Fang's ASP frequency became consistently low, with only 3.03\% (two instances) in March and 2.05\% (three instances) in May. Their frequent use of English and the absence of ASPs in Mac's language are intriguing. One explanation may be that Mac's frequent use of English reflects his expectation that Shanghai is a 'Westernized' Chinese city and the dorm room a place for an easier cultural and linguistic transition. A first-timer in China, he also regularly attended tourist events with his American peers in Shanghai. This is reminiscent of the 'Grand Tour' discourse among American colleges 
(Kinginger 2008), a discourse that imagines study abroad to be an opportunity for academic tourism and considers L2 learning non-essential. Yet, Mac was still a committed Mandarin learner with over six years of learning experience. He also extended his stay in Shanghai in order to take more language classes during the summer.

Another explanation could be related to how he was received in the dorm. His roommate Fang used the term liúxuéshēng ('foreign student') to refer to Mac, stating that foreign students should not be expected to reach discourse-level fluency in Mandarin (Field notes. 03/14/12). In China the discourse around liúxuéshēng entails a 'clearly defined' cultural role, positioning them as a group that resides in an environment isolated from the local people and has no real need to fully master the language (McDonald 2011: 201). The cultural discourse can also affect linguistic practices. As Starr (2011) shows, foreign speakers are often portrayed in pop culture as those who use ASPs extremely infrequently, which may explain the noticeable difference between Fang's ASP use with his girlfriend and with Mac. While gender and emotional engagement were salient when he spoke to his girlfriend, other factors (e.g., foreignness) might have become more relevant in his interactions with Mac. In this sense, Mac's experience seems somewhat parallel to the issue of gaijin ('foreigners,' literally 'outsiders') in studies conducted in Japan (Iino 2006; Iwasaki 2011; Siegal 1995), as in both cases the American students were exempted from local discursive norms. Yet, this interpretation is admittedly speculative. What can be observed here is that socialization of gendered L2 practices does not always occur in interactions between peers even in a college dorm room.

Comparing across the cases: A summary of the findings 
As we have seen in the focal students, gender was a very frequent theme for two of them (Ellen and Tuzi) and their Chinese roommates. In the talks that they identified to be between 'two guys' or 'girls,' gender became an important dimension along which their linguistic practices were organized. It was evoked through their constant examination of their own and each other's social practices - including language use. Both Ellen and Tuzi were evaluated as sounding like the opposite gender, but qualitative differences emerged in the ways that such incongruence was treated. For the women, they could sound 'boyish,' or 'cute' and 'sexy.' For Tuzi and Li, heterosexual masculinity became highly salient, and policing sexuality took place regularly. Linguistic practices were sanctioned accordingly. Those that were seen as incongruent with their heterosexual masculinity were rejected.

With regard to the second research question, Ellen and Tuzi both became aware of and able to use ASPs to index gender. Ellen learned to enact a 'cute girl' persona by frequently using ASPs, whereas Tuzi was socialized to avoid them and not sound 'gay' or 'like a woman.' Their changing awareness can be further inferred from their diverging patterns of ASP use over time (Table 4).

[TABLE 4 NEAR HERE]

However, such opportunities for peer LS did not occur between Mac and Fang. As shown in Table 4, they used very little Mandarin in their interactions, most of which occurred during language tutorials. During their limited recorded interactions, Mac used no ASPs. Fang also used very few ASPs when he was speaking to Mac.

\section{Discussion}


Mandarin ASPs can serve a range of pragmatic functions (Chappell 1991; Lee-Wong 1998), but in this study the focal students' ASP use highlight the aspect related to gender (Chan 1998). This finding concurs with previous research and shows that gender is indeed seen as salient among young adult L2 learners abroad (Kinginger 2008; Isabelli-Garcia 2006; Polanyi 1995; Pellegrino Aveni 2005). But more importantly, as we examine here the LS processes between the American students and their Chinese peers, what is revealed is how gender can become relevant to the organization of their L2 use. Furthermore, Ellen and Tuzi were both socialized into ways of using ASPs to index gender, which demonstrates that gender appears to be equally present for men and women when they are overseas and engage in L2 practices.

By providing evidence of peer socialization between adult L2 learners and their roommates, the study also improves our understanding of LS during a sojourn overseas. Consistent with the research on peer L1 socialization among children (e.g., Kyratzis and Guo 2001), the findings show that gender is also an important dimension along which college-age L2 learners and their peers organize their language and the social world. Peer socialization of gendered L2 practices can take place in many forms in different contexts. Ellen and Tuzi's experiences have to be understood in relation to their own personal histories and within the gender discourses in China today (W. Zhang and Kramarae 2012). We certainly need more research that addresses how L2 learners in various communities are socialized into discourses about gender, how the latter shape and transform their language development, and how learners may even become resistant to certain gendered practices (Siegal 1995). As the two young heterosexual men, Tuzi and $\mathrm{Li}$, routinely engaged in policing sexuality through language (Kiesling 2002), it also leads us to wonder how learners of not only different genders, but also varying sexual orientations, may experience differently in their LS processes with peers. While 
there is the impression that homosexual male learners tend to use ASPs more frequently after a sojourn in China (H. Du, personal communication), to date there is no published research that explores the issue of homosexuality and L2 socialization overseas.

One of the focal students, Mac, consistently used no ASPs throughout his recordings. Instead, his Chinese roommate appeared to be changing his language when speaking to a foreign student. This may be due to the fact that ASPs encode multiple social meanings, and therefore it is important to understand the 'constitutiveness' of linguistic features that can index gender (Ochs 1992: 341). Future research needs to investigate how these meanings are connected with each other and how the relationship between language and gender is mediated in Mandarin both in interactions between L1 and L2 speakers and among native speakers.

Moreover, as the findings focus on the emerging gendered Mandarin practices among China's urban youth, they raise questions for future research and pedagogical practices. New linguistic practices emerge in every language. Perhaps these emerging practices should indeed be conceptualized as a unique benefit for study abroad students, because they have access to the new forms/norms that formal instruction tends to overlook. Questions such as what forms, norms, and structures should be included in our research and pedagogy, and for what purposes, need to be constantly revisited. 


\section{Notes}

${ }^{1}$ In line with previous research on Mandarin sentence-final particles (e.g., Chappell 1991), I have chosen me to represent the particle 嘛 (in pinyin 'ma') to avoid confusion with the question marker $m a$ 吗 (in pinyin also 'ma').

${ }^{2}$ Davidson (2010: 20) reported that gender difference was no longer present among American students in Russia due to both the changing gender roles in post-Cold War Russia and the additional attention given to female students.

${ }^{3}$ It is estimated that there are over fifty programs for American college students in China (Du 2013). In a preliminary analysis of twenty-seven of them, twelve (44.44\%) reportedly offer the students the opportunity to live with a Chinese roommate, constituting the most typical living arrangement with the local people for American students in China (Diao 2013).

${ }^{4}$ All personal names in the study are pseudonyms.

${ }^{5}$ Following Kinginger's (2008) design, the focal participants were selected partially based on their varying AMSM scores. For example, Ellen's total and particle scores were both very high, whereas Tuzi's were relatively low and close to the sample means. I was unable to obtain consent from the participants with the lowest scores to record their conversations.

${ }^{6}$ Use of Shanghainese was observed for one student living with a host family, but not among those living in the dorm.

${ }^{7}$ This linguistic variety, 江淮官话, has been translated differently in research published in English. The name used here is from 'Chinese Linguistic Groups,' courtesy of University of Texas Libraries (1990). 


\section{References}

Bacon, S. 2002. 'Learning the rules: Language development and cultural adjustment during study abroad.' Foreign Language Annals 35/6: 637-646.

Baike. n.d. 'Nvzi liuxing shuaiqi mei: Jiedu nvxing nanxinghua' [Masculinity is in for women: Understanding masculine women]. Retrieved from http://w.baike.com/a544f74c077c43539325caa726266394.html.

Bourgerie, D. S. 1996. 'Acquisition of modal particles in Chinese second language learners' in McGinni, S. (ed.): Chinese pedagogy: An emerging field. Foreign Language Publications.

Brecht, R., Davidson, D., and Ginsberg, R. 1995. 'Predicting and measuring language gains in study abroad settings' in Freed (ed.).

Callier, P. 2007. 'Not so obvious: The sociolinguistic distribution of $m e$ in Mandarin Chinese.' Poster presented at New Ways of Analyzing Variation (NWAV) 36, Philadelphia, PA.

Chan, M. K. M. 1996. 'Gender-marked speech in Cantonese: The case of sentence-final particles je and jek.' Studies in the Linguistic Sciences 26: 1-38.

Chan, M. K. M. 1998. 'Gender differences in the Chinese language: A preliminary report' in Lin, H. (ed.): Proceedings of the Ninth North American Conference on Chinese Linguistics. University of Southern California.

Chappell, H. 1991. 'Strategies for the assertion of obviousness and disagreement in Mandarin: a semantic study of the modal particle me.' Australian Journal of Linguistics 11: 39-65.

Chic! Exchange. 2011. 'Nvrenmen suowei de nanhaizi qi' [The so-called boyish by women]. Retrieved from http://www.bousun.com/article/7041.html.

Chuang, T-I. 2005. 'The power of cuteness: Female infantilization in urban Taiwan.' The Stanford Journal of East Asian Affairs 5/2: 21-28. 
Cook, H. M. 2006. 'Joint construction of folk beliefs by JFL learners and Japanese host families' in DuFon and Churchill (eds.).

Cook, H. M. 2008. Socializing identities through speech style: Learners of Japanese as a foreign language. Multilingual Matters.

Cumming, S. 1984. 'The sentence in Chinese.' Studies in Language 8/3: 365-395.

Davidson, D. 2010. 'Study abroad: When, how Long, and with what results? New data from the Russian front.' Foreign Language Annals 43: 6-26.

Diao, W. 2011. 'Study abroad, participation and turn taking: A case study' in Granena et al. (eds.): Selected proceedings of the 2010 Second Language Research Forum. Cascadilla Proceedings.

Diao, W. 2013. Learning Mandarin and socializing stance during a semester in China. Unpublished doctoral thesis. Carnegie Mellon University, Pittsburgh.

Dings, A. 2007. Developing interactional competence in a second language: A case study of a Spanish language learner. Unpublished doctoral thesis. University of Texas, Austin.

Du, H. 2013. 'The Development of Chinese fluency during study abroad in China.' The Modern Language Journal 97: 131-143.

Duff, P. A. 2008a. 'Language socialization, participation and identity: Ethnographic approaches' in Martin-Jones, M., de Mejia, A-M., and Hornberger N. (eds.): Encyclopedia of language and education, Vol. 3: Discourse and education. Springer.

Duff, P. A. 2008b. Case study research in applied linguistics. Lawrence Erlbaum/Taylor \& Francis.

DuFon, M. and Churchill, E. 2006. Language learners in study abroad contexts. Multilingual Matters. 
Eckert, P. and McConnell-Ginet, S. 2013. Language and gender ( $2^{\text {nd }}$ ed.). Cambridge University Press.

Erbaugh, M. 1985. 'Sentence-final particles as an Asian areal feature' in DeLancey, S. and Tomlin, R. S. (eds.): Proceedings of the first Annual Meeting of the Pacific Linguistics Conference (pp. 84-96). University of Oregon.

Farris, C. S. 1988. 'Gender and grammar in Chinese: With implications for language universals.' Modern China 14/3: 277-308.

Farris, C. S. 1994. 'A semiotic analysis of sajiao as a gender marked communication style in Chinese' in Johnson, M. and Chiu, F. Y. L. (eds.), Unbound Taiwan: Closeups from a distance (pp. 1-29). Center for East Asian Studies

Freed, B. F. 1995. Second language acquisition in a study abroad context. John Benjamins

Freed, B. F., Segalowitz, N., Dewey, D. P. and Halter, R. 2004. 'The Language Contact Profile.' Studies in Second Language Acquisition 26: 349-356.

Goodwin, M. H. and Kyratzis, A. 2012. 'Peer language socialization' in Duranti, A., Ochs, E., and Schieffelin, B. (eds.): Handbook of language socialization. Blackwell.

Guo, Y. J. 2010. 'China's celebrity mothers: Female virtues, patriotism and social harmony' in Edwards, L. and Jeffreys, E. (eds): Celebrity in China. Hong Kong University Press.

Iino, M. 2006. 'Norms of interaction in a Japanese homestay setting: Toward two-way flow of linguistic and cultural resources' in Dufon and Churchill (eds.).

Inoue, M. 2002. ‘Gender and linguistic modernization: Historicizing Japanese women’s language' in Bucholtz, M., Liang, A. C., Sutton, L. A., and Hines, C. (eds.): Cultural performances: Proceedings of the third Berkeley Women and Language Conference. Berkeley Women and Language Group. 
Isabelli-Garcia, C. 2006. 'Study abroad social networks, motivation and attitudes: Implications for SLA' in Dufon and Churchill (eds.).

Ishita, M. 2009. 'Development of interactional competence: Changes in the use of $n e$ ' in Nguyen, H. T. and Kasper, G. (eds.): Talk-in-interaction: Multilingual perspectives (pp. 351-385). University of Hawai'i.

Iwasaki, N. 2011. 'Learning L2 Japanese "politeness" and "impoliteness": Young American men's dilemmas during study abroad.' Japanese language and literature 45: 67-106.

Ke, C. 2012. 'Research in second language acquisition on Chinese: Where we are, where we are going.' Journal of the Chinese Language Teachers Association 47/3: 43-114.

Kiesling, S. F. 2002. 'Playing the straight man: Displaying and maintaining male heterosexuality in discourse' in Campbell-Kibler, K., Podesva, R. J., Roberts, S. J., and Wong, A. (eds.): Language and sexuality: Contesting meaning in theory and practice (pp.249-266). CSLI Publications.

Kiesling, S. F. 2004. 'Dude.' American Speech 79/3: 281-305.

Kinginger, C. 2008. 'Language learning in study abroad: Case histories of Americans in France.' The Modern Language Journal 92: 1-124.

Kinginger, C. 2009. Language learning and study abroad: A critical reading of research. Palgrave Macmillan.

Kinginger, C. 2010a. 'The social turn in study abroad research.' Colloquium presentation at the American Association for Applied Linguistics. Atlanta, GA.

Kinginger, C. 2010b. 'American students abroad: Negotiation of difference?' Language Teaching 43/2: 216-227. 
Kyratzis, A. and Guo, J. 2001. 'Preschool girls' and boys' verbal conflict strategies in the United States and China.' Research on Language and Social Interaction 34/1: 45-74.

Lee-Wong, S. M. 1998. 'Face support - Chinese particles as mitigators: A study of $B A A / Y A$ and NE.' Pragmatics 8/3: 387-404.

Luke, K. K. 1990. Utterance particles in Cantonese conversation. John Benjamins.

Maxwell, J. A. 2005. Qualitative research design: An interactive approach ( $2^{\text {nd }}$ ed.). SAGE.

McDonald, E. 2011. Learning Chinese, turning Chinese: Challenges to becoming sinophone in a globalised world. Routledge.

Ochs, E. 1979. 'Transcription as theory' in Ochs, E. and Schieffelin, B. (eds.): Developmental pragmatics. Academic Press.

Ochs, E. 1992. 'Indexing gender' in Duranti, A. and Goodwin, C. (eds.): Rethinking context: language as an interactive phenomenon. Cambridge University Press.

Ochs, E. 1996. 'Linguistic resources for socializing humanity' in Gumperz, J. and Levinson, S. (eds.): Rethinking linguistic relativity. Cambridge University Press.

Ochs, E. and Schieffelin, B. 1984. 'Language acquisition and socialization: Three developmental stories' in Shweder, R. and LeVine, R. (eds.): Culture theory: Mind, self, and emotion. Cambridge University Press.

Pellegrino Aveni, V. A. 2005. Study abroad and second language use: Constructing the self. Cambridge University Press.

Polanyi, L. 1995. 'Language learning and living abroad: Stories from the field' in Freed (ed.).

Shih, Y-H. 1984. 'Cong shehui yuyanxue guandian tantao zhongwen nannv liangxing de chayi.' [A sociolinguistic study of gender differences in male and female's language in Chinese.] Jiaoxиe yи Yanjiu 6: 207-229. 
Shively, R. L. 2011. 'L2 pragmatic development in study abroad: A longitudinal study of Spanish service encounters.' Journal of Pragmatics 43: 1818-1835.

Shively, R. L. 2013. 'Learning to be funny in Spanish during study abroad: L2 humor development.' The Modern Language Journal, 97(4), 930-946.

Siegal, M. 1995. 'Individual differences and study abroad: Women learning Japanese in Japan' in Freed (ed.).

Starr, R. L. 2011. 'Variation in affective sentence-final particle use and transcription on Taiwanese Mandarin TV dramas.' Paper presented at Symposium about Language and Society (SALSA) XIX. Austin, Texas.

Talburt, S. and Stewart, M. 1999. 'What's the subject of study abroad: Race, gender and “living culture".' The Modern Language Journal 83/2: 163-175.

Tao, H. 1996. Units in Mandarin conversation: Prosody, discourse, and grammar. John Benjamins.

Twombly, S. B. (1995). 'Piropos and friendship: Gender and culture clash in study abroad.' Frontiers: The Interdisciplinary Journal of Study Abroad 1: 1-27.

Wang, C. 2010. 'Toward a second language socialization perspective: Issues in study abroad research.' Foreign Language Annals 43/1: 50-63.

Wilkinson, S. 2002. 'The omnipresent classroom during summer study abroad: American students in conversation with their French hosts.' The Modern Language Journal 86/2: $157-173$.

Wu, R-J. 2004. Stance in talk: A conversation analysis of Mandarin final particles. John Benjamins. 
Zhang, Q. 2007. 'Cosmopolitanism and linguistic capital in China: Language, gender and the transition to a globalized market economy in Beijing' in McElhinny, B. (ed.): Words, worlds, and material girls: Language, gender, globalization. Walter de Gruyter.

Zhang, W. and Kramarae, C. 2012. 'Are Chinese women turning sharp-tongued?' Discourse \& Society 23/6, 749-770.

Zhang, Z. 2008. 'Differences in conversational style for online chatting.' Journal of Xiamen University of Technology 16/1: 95-98. 